\title{
TOWARDS STRATEGIC INTENT: PERCEPTIONS OF DISABILITY SERVICE PROVISION AMONGST HOTEL ACCOMMODATION SECTOR MANAGERS
}

\author{
By \\ Simon Darcy $\mathrm{PhD}$ * \\ School of Leisure, Sport and Tourism \\ University of Technology \\ Sydney NSW Australia
}

and

Shane Pegg PhD

Senior Lecturer

School of Tourism

The University of Queensland,

Ipswich QLD Australia

*All correspondence should be directed to Associate Professor Simon, Darcy, School of Leisure, Sport and Tourism, University of Technology, Sydney

PO Box 222, Lindfield NSW 2070. AUSTRALIA

Email: Simon.Darcy@uts.edu.au 


\title{
TOWARDS STRATEGIC INTENT: PERCEPTIONS OF DISABILITY SERVICE PROVISION AMONGST HOTEL ACCOMMODATION SECTOR MANAGERS
}

\begin{abstract}
The tourism sector globally has become increasingly mindful of how an ageing population is reshaping how and in what form, services should be offered. This being particularly true of accommodation operations where there is a now a growing recognition of the commercial value for providing market groups with exceptional service. With this in mind, this study sought to ascertain the perceptions of managers in the accommodation sector towards disability service provision with a view to identifying any current service gaps or failings. An inductive, qualitative approach was used with the data collection phase incorporating a series of one on one interviews and a focus group. The in-depth interviews were conducted with 10 managers of hotels deemed to have accessible rooms that complied with the relevant building codes and standards. A focus group comprised 22 managers of hotels located in the Sydney central business district, Australia. Study findings revealed five key themes that had not been previously discussed in the literature. They were: inclusive attitudinal approach; safety; the responsibility of people with a disability to communicate their needs to the hotel; perceptions of accessible rooms by the general public; and operational processes. Related themes that emerged from the data analysis that had previously been aligned with the literature included: legislative responsibility, policy and building codes; disability as a market segment; staff awareness/training; and language, marketing, and promotion information. Implications with respect to management of accessible rooms in the accommodation sector are outlined and further areas of research are proposed.
\end{abstract}

Keywords: disability; vision; hearing; mobility; hotel; lodging; accommodation; service; social model; attitude; management perception 


\section{INTRODUCTION}

The importance of the global tourism industry appropriately addressing the basic needs of PwD (PwD) has been further reinforced through the recent establishment of the United Nations' Convention on the Rights of Persons with Disabilities (United Nations, 2006). Over the last decade, the economic contribution of $\mathrm{PwD}$ to tourism has been documented in Europe, the US, Canada and Australia (Buhalis, Michopoulou, Eichhorn, \& Miller, 2005; Darcy, 2003; Dwyer \& Darcy, 2008; HarrisInteractive Market Research, 2005; Neumann \& Reuber, 2004; Van Horn, 2007). Yet, despite such human rights and economic arguments, access to all components of tourism still remains a significant constraint for PwD (Avis, Card, \& Cole, 2005; Bi, Card, \& Cole, 2007; Darcy, 2010; Pegg \& Stumbo, 2010). For PwD, accommodation continues to be a critical constraint because of the requirements for accessible accommodation. This is because if one cannot find suitable accommodation that meets the access needs of the individual then PwD, by simple necessity, change their destination choice (Darcy, 1998, 2002; Market and Communication Research, 2002). Leiper (2003) acknowledged that the accommodation sector is a key consideration for any individual when engaged in the decision-making process for determining involvement in a tourism experience. In many cases, a PwDs prime holiday determinant is finding accommodation that can adequately meet their needs. This is in stark contrast to the nondisabled in most cases, as this group are collectively able to make do with just about any form of available accommodation if they really have a strong desire to travel to a particular destination.

There are over 650 million PwD living in the world and a growing number of people aged 65 and over that have higher levels of disability as they age (Genoe \& Singleton, 2009). Over a hundred nations have implemented disability discrimination legislation (United Nations, 2009) with the United States having the longest history with the introduction of the 
Americans with Disabilities Act, 1990. Yet, the enactment of legislation does not guarantee disability discrimination will not occur or that industry sectors proactively address disability access requirements (Grady \& Ohlin, 2009). For example, the Australian Disability Discrimination Act (DDA) was introduced in 1992 with the intent of ensuring equitable provision of services and opportunities for $\mathrm{PwD}$, accommodation choice remains today a major area of concern for individuals with disabilities. Evidence to this effect can be found in media reports, queries to national/State tourism authorities, complaint cases brought under the DDA and, formal presentations made by the Australian Human Rights Commissioner (Innes, 2006). Recently all the complaint cases brought under the DDA were analysed with one of the key findings being that approximately 12 per cent of all cases actioned were accommodation related (Darcy \& Taylor, 2009). Given this finding, it is perhaps interesting to note at this point that most system and market based approaches to conceptualising tourism are centred on the tourist and the industry responses to servicing their touristic needs (Leiper, 2003). Yet, this does not appear to be the case for PwD as a great deal of previous demand based research has identified that their needs are not being met to the same degree or do not appear to have the same priority as those of the nondisabled. (Avis, et al., 2005; Bi, et al., 2007; Burnett \& Bender-Baker, 2001; Darcy, 2002; Market and Communication Research, 2002; Turco, Stumbo, \& Garncarz, 1998; Yau, McKercher, \& Packer, 2004). It is particularly noteworthy that Darcy's (2010) review of the demand side tourism related literature suggested strongly that accommodation issues were recognised as a significant constraint to the tourism experiences of PwD. In particular, Darcy noted in his review that these constraints included: a lack of accessible accommodation; provision of accessible accommodation that did not comply with the access standards; a lack of importance attributed to the role of accommodation in terms of overall trip satisfaction trip; problems locating accessible accommodation even when it did exist; and the level, detail and accuracy of 
information about accommodation as being effectively inadequate (Darcy, 2010 p818). Thus, while it is clear from a review of the pertinent literature that there has been a great deal of investigation over the last decade into understanding the demand side of the disability tourism experience, it is also true that relatively little exploration has occurred with respect to supply side issues. This is indeed unfortunate as supply constraints are a significant issue for the industry, and for PwD in particular, as the accommodation sector is recognised as being a central pillar in terms of facilitating PwDs tourism experiences.

Given the identified lack of research endeavour in this critical area of service provision, this study sought to investigate the perceptions of accommodation managers to servicing the needs of PwD. More particularly, the study also sort to identify the approaches they take with respect their accessible accommodation stock given their policies and practices that constitute service delivery. The paper first serves to provide a suitable background and context with respect to supply side issues of the accommodation sector provisions for PwD. This is followed by an examination of the limited research that has been published to date with respect the supply side dimensions of disability and accommodation. The paper than outlines the research design used for this study before finally presenting the research findings and discussing the management implications of each.

\section{REVIEW OF SUPPLY SIDE RESEARCH}

Israeli (2002) noted that site accessibility is a precursor to tourism experiences for PwD. Yet, it is argued that many sites and accommodations do not offer the level of accessibility that many PwD require. Moreover, it is suggested that PwD use a different set of rules to evaluate sites than the nondisabled. These two points are, in themselves, critical as other researchers have consistently reported that access is a significant constraint to the tourism 
experiences of PwD (Avis, et al., 2005; Bi, et al., 2007; Burnett \& Bender-Baker, 2001; Darcy, 1998; Turco, et al., 1998). Yet, as Yau, McKercher, \& Packer (2004) have rightly argued, travelling with a disability is more than an access issue. Rather, it involves a series of interdependent and overlapping factors, each of which needing to be fully considered. For example, for a tourism trip to occur, it requires the organisation of all sectors of the tourism industry through the stages of travel (in its most simple form) - anticipation and planning; travel to the destination; on-site experience; return travel; and reflection (Clawson \& Knetsch, 1966) or through a tourism systems (Leiper, 2003). The accessibility of these processes affects the overall tourism experience for the individual involved. Yet, this experience has a further level of complexity depending upon their dimension of disability (mobility; vision; hearing; or cognitive) and their personal level of support requirements (Burnett \& Bender-Baker, 2001; Darcy, 2010).

The 1990s in Australia saw the introduction of the Disability Discrimination Act, 1992 (DDA), the first specific disability discrimination legislation introduced in Australia. The introduction of the DDA has brought with it a series of responsibilities for the providers of goods and services, and employers in Australia. The tourism industry is one industry that must respond to the challenges of the DDA. Each sector of the industry has a significant impact on the tourism experiences of PwD. While there is a growing body of literature that presents the perspective of $\mathrm{PwD}$, there is little understanding of how the industry views the provision of goods and services for PwD. Secondly, there are little understanding of how the industry has responded to the challenge of the DDA. A recent review of the complaint cases brought under the DDA has shown that there are a significant number of discriminatory practices and approximately $26 \%$ of these cases were in the tourism and hospitality sectors with $12 \%$ attributable to the accommodation sector (Darcy \& Taylor, 2009). 
Finding accommodation is more critical for PwD as accessible accommodation stock makes up such a small percentage of the overall accommodation stock (Darcy, 1998; Murray \& Murray, 1995). Little work as been done to estimate accessible accommodation stock. Murray and Murray (1995) attempted to quantify this by estimating that there are only 50 wheelchair accessible rooms in Melbourne. Similarly, Darcy (1998) identified that there was no inventory of wheelchair accessible rooms in Sydney, Australia and estimated that there were only 150 accessible rooms within the Sydney CBD room supply of 20,000 rooms or $0.75 \%$. The common factor to both studies is that most accessible accommodation stock was built from 1985 onwards due to combination of the improvement in the Australian building codes and the boom in 4 to 5 star accommodation over the 1985-1990 period (Griffin, 1989). Internationally, Tantawy, Kim, \& Pyo (2005) quantified the proportion of accessible rooms as $0.60 \%$ of room stock for Egyptian 5 star hotels.

O’Neill and Ali Knight (2000), investigated the Western Australian tourism industry perceptions of providing services for PwD as well as the level of accessibility of Western Australian hotels. The first part of the study included interviews with 15 hotel operators (hotel general managers and operational managers) from a range of two to five star properties. The outcomes of the study focused on information provision, education and training, and accessibility issues. The major finding study was that, "Without doubt the biggest threat faced by the hotel industry...is its very ignorance of its obligations under the legislation” (O’Neill and Ali Knight, p171). This finding was supported by disability organisations whose own dealings with industry reflected this lack of understanding. Yet, while the majority of hoteliers invested in continuous training and development, none included programs to train staff for service provision for PwD. This attitude could be 
attributed to the belief that PwD were not considered to be a market and, not surprisingly, the majority of operators interviewed had not actively marketed their product to PwD.

Upchurch and Seo (1996) survey of American hotel and motel operators' compliance with the Americans with Disabilities Act, 1990 (ADA) sought to measure: the level of physical compliance with the ADA; plans to meet or exceed ADA requirements; and barriers that impeded compliance. The findings from the 488 responses received suggested firstly that total compliance had not been achieved in a range of physical compliance factors (31\%) including approach, entry/elevators and rooms. Secondly, there was a lack of understanding of the legislation, although the researchers did not regard this as a barrier to compliance. Thirdly, the sector regarded financial constraints as a major barrier to compliance. Upchurch and Seo's major conclusion was that accommodation operators must properly market their products and services. Operators had not done this for PwD but did it for other market segments. In concluding they argued that operators needed to be aware that they have a social responsibility for meeting the needs of $\mathrm{PwD}$ as well as a legislative requirement to do so.

The two previous supply side perceptions studies concluded that accommodation managers did not understand the access features of their rooms or provide any level of detailed information beyond whether an establishment had a 'disabled room'. In a Turkish study Ozturk, Yayli, \& Yesiltas (2008) e-suveyed 252 hotel managers about industry readiness to meet the needs of PwD. Their findings were remarkably optimistic in that while the Turkish managers regarded disability as a new group who they had not previously considered and they recognize that sector had weaknesses in providing for the group, they believed that with strategic changes they would be able to accommodate the group. A series of structural 
recommendations were made to improve the conditions in the tourism industry for disabled customers.

Groschl (2007) undertook a review of human resource policies and practices in Canadian hotels with respect to $\mathrm{PwD}$ in the hotel sector and came to the conclusion that an understanding of the tourist behaviour of $\mathrm{PwD}$ was an often overlooked but essential component of hotel operations. Other studies have argued that accommodation providers that also have heritage considerations at particular concerns with respect to hosting PwD (Poria, Reichel, \& Brandt, 2009). The accessibility of online service provision is a known supply issue where a number of studies have shown that there are particular disadvantages that people who are blind or vision impaired in accessing hotel websites (Mills, Han, \& Clay, 2008; Williams, Rattray, \& Grimes, 2006). This is in itself a significant issue and the role and requirements for access information has been thoroughly explored by Eichhorn, Miller, Michopoulou, \& Buhalis (2008).

\subsection{Summary}

The literature reviewing the supply side accommodation managers has been sporadic, covering a number of issues and countries. The major areas investigated in the research included:

- Supply of rooms;

- responsibilities of establishments under legislative requirements;

- organisation experiences with PwD;

- disability as a market segment;

- information provision;

- human resource management practices; and

- staff training. 


\section{THE SOCIAL MODEL OF DISABILITY}

The issues identified through the supply side literature are more often seen as the problems of individuals with disabilities and equates to the dominant medical model worldview of disability as a medical problem that is a consequence of the person's impairment and their 'personal tragedy' (Oliver, 1996). A contrasting perspective suggests that the constraints are a product of the disabling tourism environment (Darcy, 2002), and in taking direction from the social model of disability, the enabling environments for disability are firmly placed on the social, cultural, economic and political agendas of government and the private sector (Barnes, Mercer, \& Shakespeare, 2010; Oliver, 1996; Swain, Finkelstein, French, \& Oliver, 2004). The social model of disability views disability as a product of the disabling environmental, social and attitudinal barriers that compound a person's impairment and prevent their participation in society. The model implies that the removal of disabling barriers serves to improve the lives of PwD, giving them the same opportunities as others on an equitable basis. The strength of the model lies in its placement of any onus for change on society as a whole, and not on the individual themself. Moreover, the model very much recognises that it is not the person's impairment that is disabling but the social exclusion that they are subjected by environmental design or poor service attitude. For example, an individual with a given mobility impairment, is not actually disabled in an environment where he or she can use suitable public transport, gain full access to buildings and their respective facilities in the same manner that an individual without an impairment might do (Barnes, et al., 2010). Figure 1 provides a simple way of conceptualising the difference between medical and social approaches to disability.

FIGURE 1 ABOUT HERE 
Critically, and as outlined earlier, one of the founding tenants of the model is that there are a series of barriers that create disabling environments for people with impairments. In the tourism sense, this equates very strongly with the identification of the constraints to travel for PwD that past demand studies have previously identified. Adding support for such an argument, Barnes (1996: 43) suggested that another component to the disabling nature of society that needed to be considered were the 'hostile social attitudes' that PwD contended with on a daily basis. As a service industry, one of the significant determinants of the quality of tourism experience is the attitude of service providers. Most PwD are pragmatists with most areas of life and do not expect their travels to be ‘trouble-free' (Walsh, 1991). However, a less than ideal access situation can be made bearable through the accurate and detailed presentation of access information made in conjunction to a positive service attitude of providers to find solutions and make people feel that they are welcome (Darcy, 2010). Yet, even in countries where disability discrimination legislation has been enacted, a significant number of complaint cases and court actions are still brought against tourism providers for discriminatory practices involving service provision (Darcy \& Taylor, 2009; Goodall, 2002; Shaw, Veitch, \& Coles, 2005).

\section{RESEARCH QUESTION}

With this background, the study sought to examine the following research questions:

1. What are the perceptions of accommodation managers to servicing the needs of PwD? and

2. What are their policies and practices to their accessible accommodation stock? 


\section{RESEARCH DESIGN}

An inductive, qualitative research design was undertaken utilising in-depth interviews, a focus group and an examination of any management information systems relating to disability. This study differed from those previously undertaken in that the population for this study was accommodation providers with rooms that comply to the Australian standards for access and mobility (Standards Australia, 2001). Using a sample frame of only including accommodation providers with accessible rooms was considered critical, as it was believed that the operators of accessible facilities could, in terms of this exploratory study at least, provide the best 'real world' insight into current levels of disability service provision as their experiences are based on a validated accommodation supply and, hence, customers with disabilities who have not been adversely affected by inaccessible supply. This was an important delimitation of the study as it was recognised from the outset that many accommodation providers have facilities that predate the relatively recent legislation and, with no immediate mandate requiring them to fully comply with the legislation, appear to have been slow to adapt their operations to facilitate an appropriate level of access for PwD. Given this fact, such operations are, in themselves, of particular interest and remain a distinct group worthy of greater research effort in the immediate future.

While there is no consolidated inventory of accessible accommodation in Australia, the two best sources of reliable accessible accommodation information for the City of Sydney were used to make preliminary hotel selections (Australian Quadriplegic Association, 2002; Cameron, 2000). These resources were used to frame a preliminary sample of accommodation to include in the study. One member of the research team was a qualified access auditor, and is a member of the Australian Association of Access Consultants. These skills provided further insight into the interview process and were drawn upon to verify the 
accessibility of the rooms. This was regarded as important because of the noted problems PwD had between booking the accommodation and the reality of using the room. Contact was then made with the establishments that were 3-5 star establishments in the Sydney. Initially 30 establishments were contacted with 15 later agreeing to be involved in the study. Due to scheduling difficulties, 12 field visits were undertaken with 10 establishments included in the final sample. Two were excluded outright from the study upon being visited due to the relative inaccessibility of the rooms that the hotel had available. As such, ten indepth interviews with accommodation providers were undertaken and this was later supplemented with in-depth interviews of an inbound operator, a peak accommodation sector provider and a specialist accommodation reviewer.

\subsection{Sample}

Interviews were requested with the staff member who had the greatest responsibility for accessible rooms and guests with disabilities. Two of the respondents also reported that they had been heavily involved with servicing the accommodation needs of members of several large PwD associations. In-depth interviews were conducted with the following types of managers: 1 Front of Office Manager of a three star motel; 1 General Manager of a five star hotel; 2 Reservations Manager of four star hotels; 2 Sales and Marketing Manager of four star hotels; 2 Director of Sales of four star hotels; 1 Director of Business Development of a 4 star hotel; and 1 Public Relations Manager of a four star hotel. Each interview lasted between 15 minutes to two hours. The manager interviewed also showed the researcher the accessible features of the hotel and the accessible accommodation rooms specifically. All accommodation rooms of the hotels met basic access provisions but not all areas of the hotels were accessible. The population, rationales and questions addressed in the focus group were the same as for the in-depth interviews. The method differed for the focus groups in that a 
notice was placed in the association newsletter/discussion list about the proposed focus group, its location, time and date. People who expressed an interest were then faxed or emailed an agenda and background issues paper that the focus group would discuss. The sessions were attended by 22 people from 14 separate Sydney hotels and included general managers, sales, marketing, promotion, building, maintenance and concierge services staff.

The focus group was facilitated by a non-disabled researcher to avoid any camouflaging of the managers' perceptions of disability that may have occurred if a PwD had facilitated the group (G. A. Ross, 1994; G. F. Ross, 2004). The focus group was observed by the principal researcher to allow for further note taking and issue preparation for the seminar. Minutes of the session were taken by another member of the research team and issues placed on a white board for participants to view as they emerged. The principal researcher, facilitator and second research team member then debriefed after the session and made further notes. The minutes were analysed for emergent themes by reading and keyword/phrase search.

\subsection{Procedures and Analysis}

The interviews and focus group used an unstructured schedule interview as this format offers flexibility in conducting the interview by varying question order, the time spent on each category and, where appropriate, by investigating other avenues identified during the interview but not covered by the schedule (Denzin, 1989: 105). Further, the unstructured schedule interview allows the schedule to be constructed in a language that recognises individual differences or industry practices and hence, the experience of the individual managers and the sector in which they operate. For example, the terminology used to describe disability (e.g. disabled, handicapped, PwD, accessible etc.) used during the interview would be dependent on the language used by individuals or in the focus group. This recognition was 
important to elicit responses that occurred in the everyday discourse of the managers in order to establish rapport and make them feel comfortable in the interview/focus group.

All interviews were tape-recorded, transcribed and spot-checked for accuracy. Each person interviewed who wished to receive a copy of the transcript was forwarded a copy. In the letter or email that accompanied the transcript, the participants were asked to perform two tasks. The first was to review the transcript to ensure that it accurately reflected their responses. The second was to take the opportunity to amend, delete or otherwise alter the text given now that they had had more time for deeper reflection on their responses. A reply-paid envelope was supplied with each transcript that could not be forwarded by email. Of the eight forwarded transcripts, two were returned. Both of the returned transcripts contained only minor editorial comments.

Initially, the data collected from the unstructured schedule interviews and open-ended survey responses were analysed using the qualitative research software, Leximancer. The Leximancer system is a new method utilising a software package to transform lexical cooccurrence information from natural language into semantic patterns. It uses a two stage process - semantic and relational - for extracting co-occurrence data using a different algorithm for each stage (Smith \& Humphreys, 2006, p. 262). Importantly, its use as a means of text mining has been shown to lead to opportunities for hoteliers to develop competitive and strategic intelligence (Lau, Lee, \& Ho, 2005). With this in mind, the software was used to analyse the study data to create a relational map. The intent of the generated map was to outline major concepts identified in the interviews as well as their relationship with other second tier variables. This initial phase of assessment, which effectively served as a means of filtering and categorising large amounts of raw data to offer the researchers some degree of 
insight into the respondents thoughts and views, was then followed by a more in-depth and traditional form of researcher intensive typological analysis. According to Howe (1988), typological analysis refers to the division of information into categories or groups '.. . on the basis of some canon for disaggregating a whole phenomenon' (1988:314). In turn, each of these typologies formed a category in which to place data. Henderson (1991) described this form of content analysis as a process used to analyse records, documents, letters, transcribed conversations or any textual item. Content analysis is essentially therefore a strategy of analysis rather than a data collection strategy. Importantly, the form of analysis undertaken drew upon the theoretical perspectives and discourses presented earlier in the paper. As such, the discourse analysis undertaken was based on the nature of ideas, texts, media, talk and behaviour of social arenas that serve to socially construct knowledge and power.

\section{FINDINGS AND DISCUSSION}

This section documents the perceptions of managers from the accommodation sector towards the provision of services for PwD. The sample represented hotels and motels built from 1961 to 2000 in the greater Sydney area. The premises ranged from three to five stars with a wide range of associated facilities and services. However, all were identified as having accessible accommodation stock as a pre-requisite for inclusion. The focus group was similarly composed with the exception that all attending were from the Sydney Central Business District rather than from the greater Sydney area. A range of issues with respect the study questions were identified through the data analysis process. While initially a range of emergent themes were identified through the use of the semantic analysis and relational map, this developed into a more detailed coding and sub coding of emergent themes. Importantly, this study revealed five themes that had not been encountered in the literature previously. These being: 
- inclusive attitudinal approach;

- safety;

- need for PwDs to communicate their needs to the hotel;

- perceptions of accessible rooms; and

- operational issues with assistive equipment.

The other issues that had been discussed in the literature previously had to do with a combination of customer service and technical considerations. They are:

- legislation, policy and building codes;

- PwD as a market segment;

- staff awareness/training; and

- language, marketing, and promotion information.

Each of the major considerations for the emergent themes will now be discussed. Table 1 provides a small selection of representative quotes for each emergent theme and is presented instead of including quotes within the body of the text.

\section{TABLE 1 ABOUT HERE}

\subsection{Inclusive attitudinal approach}

The predominant finding from the interviews and the focus group were that, regardless of legislation and policy, there was a desire by those involved to provide a high quality experience for customers with disabilities. All managers recognised that providing high quality customer service for PwD required an understanding of their individual needs and that there should be no difference in servicing PwD and the non-disabled. This suggests that from a social model perspective, the manager's attitude toward service provision for the group was inclusive and could not be considered a constraint to an enabling tourism environment (Barnes, et al., 2010; Swain, et al., 2004). This is a good starting point for any form of service provision in the hotel sector (Kuo, 2009; Saleh \& Ryan, 1991). Yet, a series of issues, omissions, differences in service provision for PwD than other guests, technical aspects, and 
built environment, communication, human resource management, marketing and promotional disabling barriers were identified that did create a disabling tourism environment. These will be discussed as part of the discussion of the emergent themes.

\subsection{Safety}

The focus group members and the number of the in-depth interviews identified the importance of being aware of PwD (particularly mobility, hearing and vision) and communicating evacuation procedures from their rooms in cases of emergency. One member of the focus group identified planning issues related to hosting conferences attended by people with vision disabilities, including safety and way finding issues as critical to customer service. The hotel had undertaken a staff-training day facilitated by the Royal Blind Society where providing orientation and wayfinding assistance included understanding the safety and evacuation procedures. It was noted that the day had proven invaluable in ensuring the successful hosting of a conference and consequently the organisation guaranteed to hold its annual conference at the hotel for a five-year period.

All aspects of safety and emergency egress are a matter considered as being critical consideration for the organisations (Fewell, 2008; Graham \& Roberts, 2000). The advantage of compliance requirements of these considerations is that the issue must be addressed by organisation's occupational health and safety programs, creating an awareness of disability issues with a resulting advantage from the consumer's perspective (Graham \& Roberts, 2000). Yet, while the safety of all guests are paramount to hotels, this consideration seemed to dominate the mindset of managers with respect to PwD. This theme may also have a connection to staff training where a greater familiarity with disability related issues may 
alleviate some of these concerns and provide a more robust understanding on which to operationalise emergency egress plans.

\subsection{Individuals to identifying their needs to the hotel}

Linked to safety was the issue of PwD identifying their disability type and access needs direct to the hotel staff. As Fewell (2008) noted, he had spent hundreds of nights in hotels while undertaking his professional commitments as a marketing executive, he had only once been asked about whether he required assistance in the event of a fire. When he inquired on that one occasion why he had in fact been asked about this issue, the response was that the hotel had just had a fire and safety inspection. This struck home for the author when a fire alarm was raised on another occasion he was in residence at a hotel yet no assistance was forthcoming (Fewell, 2008). However, even if staff are vigilant act checking with people with visible disabilities, self-identification of people with invisible disabilities, or those travelling with partners or attendants, and who therefore did not have direct contact with hotel staff is far more problematic. The example was given by one interviewee of a person with a hearing disability staying independently but who does not indicate to staff that they have a disability. If a fire alarm was to be activated and the staff were not aware of the individual, how would staff know that this person would not respond to the alarm or know to knock on the door?

This issue also concerns PwD taking responsibility for their individual safety. These findings are interesting in context to Drabek's (2000) North American survey of manager and customer attitudes towards disaster evacuations, which found that managers queried whether there is an obligation to provide assistance to PwD. Interestingly, there were major gaps between the expectation of customers and the policy of managers for disaster evacuations (Drabek, 2000, p. 55). For people with hearing impairments, they are unable to hear audible 
alarms and require the installation of visual alarm systems within their rooms. Within the Australian context, the Deafness Forum developed a relationship with an accommodation Association to agree on a minimum set of inclusions for people who are Deaf or hearing impaired. Those hotels who comply, are listed on a website that collaboratively markets to this sector of the disability community (Deafness Forum \& HMAA, 2005).

\subsection{Perception of accessible rooms by the non-disabled}

When guests with disabilities do not require accessible rooms, they may be allocated to nondisabled guests, often on a 'last sale' basis. However, managers indicated that this can cause problems. They acknowledged that many accessible rooms had historically been located in the parts of hotels with poorer vistas and were not offered across all classes of accommodation (Darcy \& Taylor, 2009; Goodall, 2002). All managers in this study reported that the non-disabled had made negative comments or complained about having to use a 'disabled room'. When probed further, the managers offered examples of the non-disabled perceptions of these rooms. There was a belief by many nondisabled people that because the rooms were 'last sale' rooms, and the way that they were sold, there was a perception among staff and guests that they were somehow of an inferior standard (Darcy, 2010; Fewell, 2008). For example, the inclusion of a hobless roll-in shower within an accessible bathroom is the feature that most non-disabled people negatively comment on to staff when staying in an accessible room. The reasons suggested were that the lack of a fixed shower screen and hob creates a sense of 'openness' that affects the perception of 'privacy' of those using the room. Further, due to the lack of a hob, if the architects or builders had not paid enough attention to the gradient of the bathroom floor there was a tendency for water to in the worst-case 'flood' the whole of the bathroom floor and spill over into the hotel room. It is also a tremendous inconvenience to PwD but one manager stated, “It can make guests feel like they are idiots!” 
Due to the creation of greater circulation space for mobility aids (including wheelchairs, commodes, shower chairs or hoists) in hotels where baths/spas and showers are standard in rooms, the provision of a hobless, accessible shower is generally made at the expense of a bath/spa. As such, a key feature of standard rooms that many nondisabled guests may be looking forward to is missing in wheelchair accessible rooms. Further, many older accessible bathrooms are of a rudimentary and 'clinical' design with managers reporting that nondisabled guests commented that the 'disabled room' had a different and aesthetically unpleasant look.

The provision of a separate bath/spa and shower was generally the standard in 4-5 star Hotels. In the last decade, there has been a push for these inclusions only to occur in five-star hotels or combining the bath and shower. However, the perception reported by hotel staff was that nondisabled guests felt that they were being 'ripped off' or disadvantaged by being given the 'disabled room' that did not have the same facilities as a standard room. The above comments varied according to the classification and age of establishment, in that the size of rooms increases with classification, as do the bathrooms. In the more spacious and better designed 5-star accommodation a bathtub and roll-in shower are provided while in most 3-4-star establishments the bath and shower are combined.

Apart from the belief that the rooms were of an inferior standard, a number of managers described an unexplained fear or aversion associated with the rooms with nondisabled people being offered the 'disabled room'. This attitude can be explained through the stigma and aversion literature and where people wish to avoid contact with others of difference (Daruwalla \& Darcy, 2005; Hahn, 1997). For whatever reason, these rooms were confronting to the non-disabled. While this research did not investigate nondisabled perceptions of 
accessible rooms, this may be a reflection of the relative status associated with disability in society. The nondisabled may have subconsciously associated the use of an accessible room as being inferior in nature or with a belief that it was below their status as nondisabled people. As one manager described, nondisabled people often believed that the hotel was somehow 'ripping them-off' or short-changing them through the provision of the accessible room, even though it has the same rack rate as any standard room. These attitudes or perceptions of disability as difference or 'fear' or aversion have been theoretically investigated through the concept of stigma or otherness in Australia and overseas (Goffman, 1963; Goggin \& Newell, 2001; Meekosha \& Dowse, 1997; Young, 1990).

One manager made the comment that the problem arose from the way the 'adapted rooms' were sold and the language that was used. Consistent with social model and cultural studies approaches to disability (Linton, 1998), the manager argued the word disabled still carries with it a negative connotation and that using adapted focuses on the features of the room rather than people's varying perception of the disabled. The policy of his hotel was to hold adapted rooms for people that required them and to use the rooms for other guests when occupancy approached capacity. In this hotel, there was no provision of a bath and all rooms could be regarded as having comparable facilities except for the hobless shower. The staff had been trained to indicate to customers that the rooms being offered were adapted rooms with extra circulation space. Rarely did any customer refuse the adapted room, the manager interpreting this as being due to the overall room quality, and the fact that the customers were just happy to have a room. This manager felt the language used and staff training were essential to the creation of a positive perception of adapted rooms. These themes and now explored further. 


\subsection{Assistive equipment}

A small number of managers interviewed and members of the focus group indicated that assistive equipment was required at some establishments where some areas of the premises were not compliant with the Building Code of Australia and the Australian Standards for access and mobility (Australian Building Codes Board, 1996; Standards Australia, 2001). The equipment included ramps, stair climbers, inclinators and porch lifts. Managers reported that staff were generally trained in the use of the equipment during their induction program at the hotel and customers were told upon check-in of the areas of the hotel that required assistive equipment and how to contact staff to deploy such equipment if needed.

As argued by Preiser and Ostroff's discussion of universal design (2001), these procedures were put in place in order to provide PwD with a comparable level of service to other customers. Staff from one hotel in particular reported that it regularly had groups of wheelchair users who did require the use of portable ramps to reach one of the hospitality areas. The ramp was fixed in placed upon their arrival until after they had booked out of the premises. When probed as to why they had not made that area accessible on a more permanent basis, the manager stated that “we hadn't considered doing that”. A statement that serves to support the argument raised previously by social model approaches that often the constraints facing PwD are a product of the disabling tourism environment rather than anything related specifically to the individual themself. Yet, rather than proactively addressing the identified built environment constraint by creating an enabling environment (Barnes, et al., 2010; Swain, et al., 2004), management placed this group at a disadvantage by having to ask for "special provisions" each time they want to access an area, which compromised the equality of experience and independence of access. 


\subsection{Legislation, policy and building codes}

Unlike the research findings reported by O’Neill and Ali Knight (2000), most managers involved in this study recognised that recent building regulations dictated that modern hotels should have what they referred to as 'disabled rooms'. The understanding of what constituted accessible rooms varied greatly among those interviewed and those at the focus group and was very much dependent on the role and previous employment history of the manager. By and large, building/maintenance managers were more aware of disability related standards than were their sales, marketing and reception colleagues. Yet, there was no recognition that access extended beyond the guest rooms to all areas of the hotel. Many managers recognised problems with the accessibility of their general facilities but only a few had a strategy in place to address these issues. There was also less awareness of how the legislation and policy affected all areas of service provision so that customers with disabilities should have an equality of experience to that of the nondisabled, which is the basis of the international convention (United Nations, 2006). The disabled rooms were the focus of access provision but did not extend to understanding the totality of the tourism experience including gymnasiums, swimming pools, outdoor environments, nightclubs and bars.

It was clear from the responses that some managers (particularly general, building and maintenance managers) had detailed experience and understanding of the Building Codes of Australia (BCA). One general manager was directly involved with initiative a Western Australian initiative to raise disability awareness amongst the sector (Disability Services Commission (WA), 1997). This manager recognised the importance of the age of the premise, the degree of interaction of staff with $\mathrm{PwD}$, and the approach taken by management to incorporate disability issues into staff training. The hotel had a decade-long involvement with a major disability-sporting event and this on-going experience had helped develop a 
greater staff understanding about their responsibilities under the legislation. For example, the manager recognised that the premises had a number of substantial access-related constraints. Foremost being that the hotel had only two accessible rooms in one vista and several inaccessible public areas. Such a limited range of opportunities for PwD is consistent with the findings of Tantawy, Kim and Pyo (2005) who, in a study of Egyptian Hotels quantified the proportion of accessible rooms as being less than 1 per cent despite the wide range of disabilities of tourists that desired to visit the country. Yet, these significant structural constraints to an enabling tourism environment were considered easy to overcome in the Turkish context (Ozturk, et al., 2008), which suggests a clear lack of understanding of the complexity of the structural built environment context (Darcy, 2010).

While there will always be access issues to be addressed for individuals, the manager of the hotel highlighted above also recognised that operationally they had extra responsibility to accurately inform PwD as to the establishment's level of provision and to make whatever 'modifications or adjustments' were necessary to facilitate a more satisfying experience. Successful accessible tourism regions and operations had been noted for their detailed access information provision to provide a $\mathrm{PwD}$ with an informed position on which to make a decision about the suitability of the accommodation or experience for their needs (Darcy, 2010; Darcy, Cameron, \& Pegg, 2010; Darcy \& Dickson, 2009). Interestingly, many of these adaptations reported by the various hotel managers were relatively simple in nature (e.g. raising the height of beds or removing bathroom doors to increase circulation space) yet were critical to meeting the expressed needs of the customer. That stated, it need also be acknowledged that these examples were positive proof of the little things that could be done to meet the expressed needs of a customer with a disability, the greater reality was that these adaptations were possible because of the physical abilities of elite athletes with disabilities. 
Thus, these same adaptations might not assist the average PwD. As the manager noted, his level of understanding and responsibility would not have been possible without his involvement in an educative program and on-going experiences with PwD through the hotel's activities. Yet, while the UN Convention and the DDA place a high value on education, there has been relatively little investment by tourism industry associations or businesses in disability related training.

\subsection{PwD as a market segment}

While there was generally a greater level of awareness of relevant disability legislation from an operational perspective, this could not be said of the reception, sales and marketing staff. Not surprisingly given this observation, was that there was little development of PwD as a market segment despite a series of studies on the economic contribution of disability to tourism (Buhalis, et al., 2005; Darcy, 2003; Dwyer \& Darcy, 2008; HarrisInteractive Market Research, 2005; Neumann \& Reuber, 2004; Van Horn, 2007). The most common response was that if there were an expressed demand by PwD for facilities and services then they would see if this could be accommodated within the hotel. When probed further about what constituted accommodating this group the responses were vague. None of the hotels had actively pursued disability as a market segment. Of the four managers who had experience with PwD, two involved wheelchair-sporting events, some of which began with Paralympic involvement during the Sydney 2000 Olympic and Paralympic Games, and one had experience in hosting a conference for people who were blind. However, this involvement was reactive rather than strategic as the managers had responded to approaches by disability organisations. Apart from the previously discussed physical adaptations for people with mobility disabilities and specific training for people with vision disabilities, no other strategies had been implemented to meet the needs of this market segment. 
The different dimensions of disability were unequally recognised by the managers. The focus of access issues was on access for wheelchair users, which is consistent with the requirements under the Australian Building Codes and relevant standards for access on mobility. There was some recognition of the needs of people with vision impairment or who are blind and to a lesser extent people with hearing impairments or who are Deaf. However, there was no recognition of people with cognitive or psychiatric disabilities. The management information systems of the establishments reflected this narrow consideration of the four major dimensions of access requirements. The major industry Association that provides accommodation information, also only focused on mobility access until the withdrawal of even this limited system of access awareness in 2006 (AAA Tourism, 2006).

A number of managers recognised the link between ageing and disability, and the substantial market that seniors offer. This was based on the demand from some seniors for accessible accommodation. One manager saw adapted rooms as having extra features to market in a very positive way to seniors. The features that seniors liked in accessible rooms were the handrails for mobility support, the hobless shower as a safety feature and the extra circulation space in rooms. These features that people with ambulant disabilities were fully examined in other Australian studies (Darcy, 2010; Ruys \& Wei, 1998).

It appears that a series of industry awareness strategies promoted by the Commonwealth and state governments appeared to have had little impact on the managers interviewed (Australian Human Rights Commission, 2009; Disability Services Commission (WA), 2000; Office of National Tourism, 1998). These findings were supported a decade earlier by the observation of the CEO of the Tourism Task Force, a tourism industry lobby group who stated: 'To date, 
the tourism industry has not been smart enough to tap into the potential of the market or not good enough in meeting its moral responsibility in providing access for PwD’ (Brown, 1999). Little appears to have changed up to 2010.

\subsection{Staff awareness and training}

One manager stated, 'Staff training is crucial to the way PwD are treated' and went on to explain that if staff have not had experience of PwD then they were unsure of how to approach people or act in an appropriate manner. An issue identified initially by the researchers when using the Disability Conceptual Map as a tool to better detail the links between staff, their training, and the impact each had on the service provided and the customer more generally. Having accessible premises was the starting point for providing services for PwD but if the staff themselves were ill prepared to provide appropriate customer service then a customer's needs cannot be adequately addressed. Three hotels represented among the interviewees and focus group members had undertaken, or were undertaking, disability awareness training. Two of these hotels had had experience with athletes with disabilities and were to be involved with the 2000 Paralympic Games in Sydney, Australia. The third hotel had a number of access constraints that required the use of assistive equipment. Another manager noted that any training must be undertaken at all levels of the hotel to ensure a 'quality management' approach to servicing PwD. This was particularly important for managers of front line staff who were the ones in most contact with guests but which are also the positions that had the highest rate of staff turnover. It was observed that, unless managers discuss disability issues with new staff or formally have in place an orientation program that includes disability awareness, these issues could become lost with staff turnover. Staff turnover being a major issue for establishments that used high levels of casuals in customer service provision and is a noted industry-wide issue (Weaver \& 
Opperman, 2000). Yet, despite this recognition, and consistent with the arguments presented previously by Stumbo and Pegg (2005) when outlining their service concerns with respect to tourists with disabilities, , it was clear from the study findings that the majority of managers interviewed had not previously planned any disability awareness training.

Another manager who was a graduate of a private tourism college said there had been no inclusion in his course curriculum. However, he had undergone disability awareness training as part of customer service training for Stadium Australia's Olympic involvement and was impressed with what he had learnt and how it could be applied in his current position. This manager also believed that it was an area that should be part of the tourism curriculum. Training issues have been discussed in the Australian context in the literature (Daruwalla, 1999; Daruwalla \& Darcy, 2005; G. F. Ross, 2004; Weiler \& Muloin, 1990), but the extent to which disability issues are included in tourism training curricula is unknown.

\subsection{Language, marketing, promotion and information distribution}

In the introduction to this paper, it was noted by the authors that language and terminology is an important signifier of the conceptual approach to disability. The discourse of language has been identified as a priority area in the social model as a way to claim and create an appropriate disability discourse (Corbett, 1996; Corker \& French, 1999; Linton, 1998). This issue was explored in the interviews and focus group in regard to managers' own use of terminology and the language and terminology used in their marketing and promotion and contrasted to appropriate language in the Australian context (Hume, 1994; Physical Disability Council of NSW, 2008). Generally, most of the managers interviewed referred to the disabled, the handicapped or to their disabled rooms or facilities. From a disability perspective, it can be argued that this type of language is stigmatising and creates a sense of 
otherness (Goffman, 1997; Young, 2000). Some used person-first language, discussing the needs of PwD and referred to their facilities as being accessible or our accessible rooms. Some sought to avoid direct reference to PwD at all. Contrasting discourses in the interviews existed where one manager referred to the hotel's adapted rooms as being a positive marketing label to explain to guests the extra features the rooms had, while another told the non-disabled guests that they would have to make do as 'all that's left is the disabled room' and they are sorry for not having a 'normal' room available.

An extension of the role of language and discourse in relation to disability was the absence of documentation of the accessible features of the premises or the accessible room. Most managers recognise that they had one or a number of 'disabled rooms' but had no further information available to describe the rooms in any detail. For example, none had bothered to develop a system of access audit or information collation. Consequently, it had not occurred to any of those interviewed to undertake marketing, promotion or distribution of information relating to the accessible features of the establishments to PwD, even though some managers had a sound understanding that their facilities were well suited to PwD. For example, one manager, whose hotel has nine accessible rooms, was unaware that a hotel with this number of accessible rooms was unusual, given that most hotels rarely had more than three accessible rooms. When it was brought to this manager's attention that the hotel could be considered to be at a competitive advantage in attracting the business of groups of PwD, the response was: 'I hadn't thought about it that way before'. Most managers had no idea that specialist information collection exercises existed to establish databases on accessible rooms. They were surprised to hear of any initiatives for listing accessible accommodation and were unaware of commercially available access guides. The process for dealing with an inquiry 
from PwD was to respond to see if they could cater for the group within their own establishment on a case-by-case basis.

Consistent with the findings of McKercher et al. (2003), with respect to travel agents perceptions of PwD, for the majority of the managers interviewed the issue of 'accessible accommodation' meant accessibility of a hotel's 'disabled rooms'. It is fair to say that most recognised some key components of such rooms: for example, width of doorways, circulation space in the rooms, hobless shower and bed height were commonly mentioned. It was only after further probing however that other accessible features and amenities of hotels were discussed (e.g. restaurants, conference facilities etc.). Sometimes this was because there was recognition that the hotel had some access-related problems in regard to certain of these other amenities - or were disabling environments from the social model perspective. For example, many of the hotels did not provide access to recreation facilities such as gymnasia or swimming pools. A number of managers knew something of the accessibility of the surrounding environment and the location of accessible public transport. Yet, when asked what information they provided when they received an inquiry for an accessible room, they all stated that they simply confirmed that the hotel had 'disabled rooms'. No other information was provided on the accessible features of the establishments. Some reported that people would ask very specific information (e.g. measurements) and they would try and provide that information to the customer if they could. Yet, even when these specifics were asked for, the information was only provided on an ad hoc basis without the thought of developing detailed information provision for $\mathrm{PwD}$ as outlined by the literature as a foundation for servicing the market (Eichhorn, et al., 2008). 
The room-related focus could be attributed to the questions that may be asked by PwD when making an inquiry about the hotels. This is not surprising given the experiences documented in other research in the literature review relating to the constraint of finding accessible rooms (Darcy, 2010). Given the urban focus of the research, this may not fully reflect experiences of staff in non-metropolitan resort settings where these recreational features and surrounding tourist attractions are far more prominent in marketing their facilities and services. Yet it need be recognised that in the absence of clear empirical evidence to support this line of argument this must remain, for now at least, an assertion by the authors of this paper about service provision in regional and rural locales of Australia for PwD that need be fully tested in the near future through rigorous research effort.

With respect to information networks used by the accommodation sector, these extend beyond the consumer and the accommodation provider to the communication chain between the consumer, wholesale and retail intermediary. While accommodation providers expressed a trust in their intermediaries to showcase their properties, they were uncertain as to how the intermediaries represented their accessible product. This situation arguably arose because of the lack of information provision about their accessible product and what the intermediaries understood accessibility by the access needs of PwD. An issue consistent with that identified previously by McKercher et al. (2003) in their study of travel agents perceptions of PwD. An example was given of a three-week period from the time of receiving a booking from a wholesaler about a group's access needs and those needs being fully articulated to the accommodation provider. As another manager asked: 'What do retailers say about our accommodation to potential guests who make an inquiry?' Retail travel agents often tell PwD that they would be best advised to organise the trip and accommodation themselves and have 
been identified as a weakness in the planning phase of the experiences of PwD (Darcy, 1998; McKercher, Packer, Yau, \& Lam, 2003).

Lastly, it was recognised by those managers involved in this study that networking was an important part of sharing disability-related information. Yet, it must be reported that this research study was the first opportunity that most had had to discuss disability-related issues.

\section{CONCLUSION}

This paper has presented an investigation into the perceptions of accommodation managers toward service provision for PwD. The predominant finding from the interviews and the focus group were that, regardless of legislation and policy, there was a desire by those involved to provide a high quality experience for customers with disabilities. All managers recognised that providing high quality customer service for people required an understanding of their individual needs and that there should be no difference in servicing PwD and the nondisabled. This is critical for as noted by Tiddy (2001), disability is more than just a question of law and ethics. Rather, by creating enabling accommodation environments and welcoming service attitudes towards PwD ensures a competitive business advantage due ageing population and the need to be at the forefront of innovation in a competitive business environment.

While the managers had an inclusive attitude towards the group, there were other practices and omissions that saw service provision for PwD treated differently to that of other customers. Five issues were identified by the managers that had not previously been found in the literature. These were safety; the need for people with a disability to communicate their needs to the hotel; the perception of the accessible rooms by the nondisabled and operational 
nature of assistive equipment. These issues are important considerations that identified the more sophisticated understanding of disability and the nature of accessible accommodation than had been identified in past literature. Yet, this study has shown that far from embracing disability and access there are still a series of omissions that maintain a disabling accommodation environment. These include no pro active approach to developing disability as a market segment, low levels of disability awareness/training within the majority of organisations and an omission of specific marketing and promotion information identified by PwD as central to their accommodation choice decisions. Not surprisingly, Groschl (2007) in undertaking a review of human resource policies and practices with respect to PwD in the hotel sector, came to the conclusion that disability was overlooked as an essential component of hotel operations. By overlooking the detail of their needs, their inclusive attitude will not be backed up by enabling accommodation environments and practices (Barnes, et al., 2010; Swain, et al., 2004).

Significantly, the study findings showed a lack of understanding by managers in what constitutes suitable accessible accommodation and an omission to document, market and promote this information to the group. This communicative environment is as important as the physical environment in requiring enabling practices to break down the constraint of poor quality information provision by hotel operations to the group. While other studies have identified the constraints that online environments create for people with vision impairments, this lack of detailed accommodation information specifically targeted at the needs of PwD is just as disabling to accommodation and, hence, destination choice (Eichhorn, et al., 2008). This notion is not lost on tourism authorities in South Africa (Els, 2009), Australia (Darcy et al., 2008; Dickson \& Hurrell, 2008) and Finland (Dowen \& Smith, 2007) who have recently 
sought to better educate travel and tourism operators about the opportunities this market presents and the enabling online and destination environment that they require.

Whether the travel of PwD is cased in terms of 'Disabled travel', 'Inclusive travel', 'BarrierFree' or 'Accessible tourism', the reality for hotel operations is that PWD in conjunction with the ageing of the population is a market that is a growing and significant segment of the tourism industry, which cannot be ignored under the law or from a business perspective (Buhalis, et al., 2005; Darcy, 2003; Dwyer \& Darcy, 2008; HarrisInteractive Market Research, 2005; Neumann \& Reuber, 2004; Van Horn, 2007). It is in the business interests of hotels to better align their practices and services with the consumer interests of PWD (Stumbo \& Pegg, 2005). For instance, PwD often travel with others and this is in itself a wider market often not considered. As such, it is argued by a range of researchers (Genoe \& Singleton, 2009; Poria, et al., 2009) that businesses that recognise and accommodate the needs of PwD are, even if perhaps unintentionally at first, strategically aligning themselves with the latent needs of an ageing population, which will increasingly seek out accessible tourism experiences within their family and social constructions. Of course, accommodation will be the critical determinant to their destination choice. 


\section{REFERENCES}

AAA Tourism. (2006). Withdrawal of accessibility rating icons. Retrieved 8 August, 2006 Australian Building Codes Board. (1996). Building Code of Australia. Canberra: CCH Australia.

Australian Human Rights Commission. (2009). Missed Business - How to attract more customers by providing better access to your business (Vol. 2009, Available from http://www.hreoc.gov.au/disability_rights/buildings/missed_business/index.html

Australian Quadriplegic Association. (2002). Access Sydney: the Easy Guide to Easy Access (1st ed.). Sydney: Australian Quadriplegic Association.

Avis, A. H., Card, J. A., \& Cole, S. T. (2005). Accessibility and Attitudinal Barriers Encountered by Travelers With Physical Disabilities Tourism Review International, 8, 239-248.

Barnes, C. (1996). Theories of disability and the origins of the oppression of disabled people in western society. In L. Barton (Ed.), Disability and Society: Emerging Issues and Insights (pp. 40-59). New York: Longman.

Barnes, C., Mercer, G., \& Shakespeare, T. (2010). Exploring disability: a sociological introduction (2nd ed.). Malden, Mass: Polity Press.

Bi, Y., Card, J. A., \& Cole, S. T. (2007). Accessibility and Attitudinal Barriers Encountered by Chinese Travellers with Physical Disabilities. Int. J. Tourism Res, 9, 205-216.

Brown, C. (1999, 16 September). Address to Gold Medal Disability Access Strategy Hobart Symposium. $\quad$ Retrieved 10 March, 2000, from www.goldmedal.gov.au/symphobart.html

Buhalis, D., Michopoulou, E., Eichhorn, V., \& Miller, G. (2005). Accessibility market and stakeholder analysis - One-Stop-Shop for Accessible Tourism in Europe (OSSATE). Surrey, United Kingdom: University of Surrey.

Burnett, J. J., \& Bender-Baker, H. (2001). Assessing the travel-related behaviors of the mobility-disabled consumer. Journal of Travel Research, 40(1), 4-11.

Cameron, B. (2000). Easy Access Australia (2nd ed.). Kew, Vic: Kew Publishing.

Clawson, M., \& Knetsch, J. L. (1966). The Economics of Outdoor Recreation. Baltimore: Johns Hopkins Press.

Corbett, J. (1996). Bad-mouthing: the language of special needs. London; Washington, D.C.: Falmer Press.

Corker, M., \& French, S. (1999). Disability discourse. Buckingham: Open University Press.

Darcy, S. (1998). Anxiety to Access: The Tourism Patterns and Experiences of New South Wales People with a Physical Disability: Tourism New South Wales.

Darcy, S. (2002). Marginalised participation: Physical disability, high support needs and tourism. Journal of Hospitality and Tourism Management, 9(1), 61-72.

Darcy, S. (2003, 5-8 February). Disabling journeys: The tourism patterns of people with impairments in Australia. Paper presented at the Riding the Wave of Tourism and Hospitality Research, CAUTHE - Southern Cross University, Lismore.

Darcy, S. (2010). Inherent complexity: Disability, accessible tourism and accommodation information preferences. Tourism Management, 31(6), 816-826.

Darcy, S., Cameron, B., Dwyer, L., Taylor, T., Wong, E., \& Thomson, A. (2008). Visitor accessibility in urban centrespp. 75). Available from http://www.crctourism.com.au/BookShop/BookDetail.aspx?d=626

Darcy, S., Cameron, B., \& Pegg, S. (2010). Accessible tourism and sustainability: a discussion and case study. Journal of Sustainable Tourism, 18(4), 515 - 537. 
Darcy, S., \& Dickson, T. (2009). A Whole-of-Life Approach to Tourism: The Case for Accessible Tourism Experiences. Journal of Hospitality and Tourism Management, 16(1), 32-44.

Darcy, S., \& Taylor, T. (2009). Disability citizenship: An Australian human rights analysis of the cultural industries. Leisure Studies, 28(4), 419-441.

Daruwalla, P. S. (1999). Attitudes, Disability and the Hospitality and Tourism Industry. Unpublished Ph.D. Thesis, University of Newcastle, Newcastle, NSW.

Daruwalla, P. S., \& Darcy, S. (2005). Personal and Societal Attitudes to Disability. Annals of Tourism Research, 32(3), 549-570.

Deafness Forum, \& HMAA. (2005). Accommodation Industry Voluntary Code of Practice for the Provision of Facilities for the Deaf and Hearing Impaired Retrieved 13 Feb, 2010, from http://www.deafnessforum.org.au/index.php?q=accessible-accomodation

Denzin, N. K. (1989). The Research Act: a Theoretical Introduction to Sociological Method. New York: Prentice Hall.

Dickson, T., \& Hurrell, M. (Writer). (2008). Alpine Accessibility Tourism Toolkit [DVD]. In T. Dickson (Producer). Australia: Australian Tourism Development Program/Australian Federal Government Initiative.

Disability Services Commission (WA). (1997). Accessing New Markets: Tourism Industry Think Tank Report. West Perth: Western Australia Disability Services Commission.

Disability Services Commission (WA). (2000). You can make a difference to customer service for people with disabilities [kit]: hospitality, tourism, retail \& entertainment industries. West Perth, W.A.: Disability Services Commission.

Dowen, C., \& Smith, D. (2007, 7 Dec). Finns are easeier here for clients with disabilities. Travel Trade Gazette, 48.

Drabek, T. E. (2000). Disaster evacuations: tourist-business managers rarely act as customers expect. The Cornell Hotel and Restaurant Administration Quarterly, 41(4), 48-57.

Dwyer, L., \& Darcy, S. (2008). Chapter 4 - Economic contribution of disability to tourism in Australia. In S. Darcy, B. Cameron, L. Dwyer, T. Taylor, E. Wong \& A. Thomson (Eds.), Technical Report 90040: Visitor accessibility in urban centres (pp. 15-21). Gold Coast: Sustainable Tourism Cooperative Research Centre.

Eichhorn, V., Miller, G., Michopoulou, E., \& Buhalis, D. (2008). Enabling access to tourism through information schemes. Annals of Tourism Research, 35(1), 189-210.

Els, K. (2009, August/September). Disabled tourism gaining popularity. Tourism News, 3.

Fewell, A. (2008). Hotels must wake up to disability. . Caterer \& Hotelkeeper, 198, 16.

Genoe, R., \& Singleton, J. (2009). World demographics and their implications for therapeutic recreation. In N. J. Stumbo (Ed.), Professional issues in therapeutic recreation on competence and outcomes. Champaign, Il: Sagamore.

Goffman, E. (1963). Selections from Stigma. In L. J. Davis (Ed.), The Disability Studies Reader (pp. 205-215). London: Routledge.

Goffman, E. (1997). Selections from Stigma. In L. J. Davis (Ed.), The Disability Studies Reader. London: Routledge.

Goggin, G., \& Newell, C. (2001). Crippling Paralympics? Media, disability and Olympism. Media International Australia, 97(Nov), 71-83.

Goodall, B. (2002, 16-18 May). Disability discrimination legislation and tourism: The case of the United Kingdom. Paper presented at the Tourism and Well Being - 2nd Tourism Industry and Education Symposium, Jyvaskyla, Finland.

Grady, J., \& Ohlin, J. B. (2009). Equal access to hospitality services for guests with mobility impairments under the Americans with Disabilities Act: Implications for the hospitality industry. International Journal of Hospitality Management, 28(1), 161169. 
Graham, T. L., \& Roberts, D. J. (2000). Qualitative overview of some important factors affecting the egress of people in hotel fires. International Journal of Hospitality Management, 19(1), 79-87.

Griffin, T. (1989). Hotel development: the downtown Sydney case. In J. Blackwell \& L. Stear (Eds.), Case Histories of Tourism \& Hospitality (pp. 317-333). Sydney: AustralianInternational Magazine Services.

Gröschl, S. (2007). An exploration of HR policies and practices affecting the integration of persons with disabilities in the hotel industry in major Canadian tourism destinations. International Journal of Hospitality Management, 26(3), 666-686.

Hahn, H. (1997). Advertising the Acceptably Employable Image. In L. J. Davis (Ed.), The Disability Studies Reader. London: Routledge.

HarrisInteractive Market Research. (2005). Research among adults with disabilities - travel and hospitality. Chicago: Open Doors Organization.

Henderson, K. A. (1991). Dimensions of Choice: A Qualitative Approach to Recreation, Parks, and Leisure Research. State College, PA: Venture Publishing.

Hume, J. (1994). Media Guidelines. Sydney: Disability Council of NSW.

Innes, G. (2006, 21 January). Building access and no holiday for the disabled. The Daily Telegraph.

Israeli, A. (2002). A preliminary investigation of the importance of site accessibility factor for disabled tourists. Journal of Travel Research, 41(1), 101-104.

Kuo, C. (2009). The managerial implications of an analysis of tourist profiles and international hotel employee service attitude. International Journal of Hospitality Management, 28(3), 302-309.

Lau, K.-N., Lee, K.-H., \& Ho, Y. (2005). Text Mining for the Hotel Industry. Cornell Hotel and Restaurant Administration Quarterly, 46(3), 344-362.

Leiper, N. (2003). Tourism management (3rd ed.). Sydney: Hospitality Press.

Linton, S. (1998). Claiming disability: knowledge and identity. New York: New York University Press.

Market and Communication Research. (2002). People with Disabilities: a Market Research Report. Brisbane: Tourism Queensland - Special Interest Tourism Unit.

McKercher, B., Packer, T., Yau, M. K., \& Lam, P. (2003). Travel agents as facilitators or inhibitors of travel: perceptions of people with disabilities. Tourism Management, 24(4), 465-474.

Meekosha, H., \& Dowse, L. (1997). Distorting Images, Invisible Images: Gender, Disability and the Media. Media International Australia, 84(May), 91-101.

Mills, J. E., Han, J.-H., \& Clay, J. M. (2008). Accessibility of Hospitality and Tourism Websites: A Challenge for Visually Impaired Persons. Cornell Hospitality Quarterly, 49(1), 28-41.

Murray, A., \& Murray, M. (1995). Submission on Accessible Accommodation Stock to the Industry Commission Inquiry: Toursim Accommodation and Training.

Neumann, P., \& Reuber, P. (2004). Economic Impulses of Accessible Tourism for All (Vol. 526). Berlin: Study commissioned by the Federal Ministry of Economics and Technology \& Federal Ministry of Economic and Labour (BMWA).

O'Neill, M., \& Ali Knight, J. (2000). Disability tourism dollars in Western Australia hotels. FIU Hospitality Review, 18(2), 72-88.

Office of National Tourism. (1998). Tourism Challenge: Access for All. Canberra: Office of National Tourism.

Oliver, M. (1996). Understanding Disability: From Theory to Practice. Basingstoke, Houndmills: Macmillan. 
Ozturk, Y., Yayli, A., \& Yesiltas, M. (2008). Is the Turkish tourism industry ready for a disabled customer's market?: The views of hotel and travel agency managers. Tourism Management, 29(2), 382-389.

Pegg, S., \& Stumbo, N. (2010). Creating opportunities and ensuring access to desirable heritage and cultural tourist services and leisure experiences. In B. Prideaux, D. J. Timothy \& K. Chon (Eds.), Cultural and Heritage Tourism in Asia and the Pacific (pp. 250-256). New York, USA Routledge.

Physical Disability Council of NSW (Ed.). (2008). Words Matter: Language Guide. Sydney: Physical Disability Council of NSW.

Poria, Y., Reichel, A., \& Brandt, Y. (2009). People with disabilities visit art museums: an exploratory study of obstacles and difficulties. Journal of Heritage Tourism, 4(2), 117 $-129$.

Preiser, W. F. E., \& Ostroff, E. (2001). Universal Design Handbook. New York: McGrawHill.

Ross, G. A. (1994). Attitudes Towards The Disabled In Destination Marketing Organizations (Marketing Organizations). Unpublished Ph.D. Thesis, Virginia Polytechnic Institute and State University.

Ross, G. F. (2004). Ethics, trust and expectations regarding the treatment of disabled staff within a tourism/hospitality industry context. International Journal of Hospitality Management, 23(5), 523-544.

Ruys, H., \& Wei, S. (1998). Accommodation needs of mature Australian travellers. Australian Journal of Hospitality Management, 5(1), 51-59.

Saleh, F., \& Ryan, C. (1991). Analysing service quality in the hospitality industry using the SERVQUAL model. The Service Industries Journal, 11(3), 324-345.

Shaw, G., Veitch, C., \& Coles, T. I. M. (2005). Access, disability, and tourism: changing responses in the United Kingdom. Tourism Review International, 8(3), 167-176.

Smith, A., \& Humphreys, M. (2006). Evaluation of unsupervised semantic mapping of natural language with Leximancer concept mapping. Behavior Research Methods, 38(2), 262.

Standards Australia. (2001). AS 1428.1 Design for access and mobility - General requirements for access - New building work. Homebush, NSW: Standards Australia.

Stumbo, N. J., \& Pegg, S. (2005). Travelers and tourists with disabilities: a matter of priorities and loyalties. Tourism Review International, 8(3), 195-209.

Swain, J., Finkelstein, V., French, S., \& Oliver, M. (2004). Disabling barriers - enabling environments (3rd ed.). London: Sage Publications Ltd.

Tantawy, A., Kim, W. G., \& Pyo, S. (2005). Evaluation of Hotels to Accommodate Disabled Visitors. Journal of Quality Assurance in Hospitality \& Tourism, 5(1), 91 - 101.

Tiddy, J. (2001). It's Just Not Fair: Overcoming discrimination in Australia. Sydney: ABC Books.

Turco, D. M., Stumbo, N., \& Garncarz, J. (1998). Tourism Constraints - People with Disabilities. Parks and Recreation Journal, 33(9), 78-84.

United Nations. (2006). Convention on the Rights of Persons with Disabilities. New York http://www.un.org/esa/socdev/enable/rights/convtexte.htm: United Nations General Assembly A/61/611 - 6 December 2006.

United Nations. (2009, 2 June 2009). Enable. from http://www.un.org/disabilities/

Upchurch, R. S., \& Seo, J. W. (1996). Civic responsibility and market positioning: complying with the Americans with Disabilities Act. Facilities, 14(5/6).

Van Horn, L. (2007). Disability Travel In The United States: Recent Research And Findings. Paper presented at the 11th International Conference on Mobility and Transport for 
Elderly and Disabled Persons (TRANSED) - "Benchmarking, Evaluation and Vision for the Future". , June 18-22, 2007, at the Palais des congrès de Montréal.

Walsh, A. (1991). Nothing Ventured: Disabled People Travel the World. Kent: Harrap Columbus.

Weaver, D., \& Opperman, M. (2000). Tourism Management. Milton Park, Queensland: John Wiley and Sons Australia Pty Ltd.

Weiler, B., \& Muloin, S. (1990). Introducing Specific Populations into curricula in Tertiary Tourism Education in Australia. Paper presented at the Australian National Tourism and Education Conference, Canberra.

Williams, R., Rattray, R., \& Grimes, A. (2006). Meeting the On-line Needs of Disabled Tourists: an Assessment of UK-based Hotel Websites. International Journal of Tourism Research, 8(1), 59.

Yau, M. K.-s., McKercher, B., \& Packer, T. L. (2004). Traveling with a disability: More than an Access Issue. Annals of Tourism Research, 31(4), 946-960.

Young, I. M. (1990). Justice and the politics of difference. Princeton, New Jersey: Princeton University Press.

Young, I. M. (2000). Inclusion and democracy. Oxford: Oxford University Press. 
Figure 1: Conceptualising the difference between medical and social approaches to disability

\section{Conceptualising the difference between the} Medical Model vs Social Model of Disability

Why can't I access all areas of the hotel?

- Answer: Medical Model

1. Because of my disability "I can't walk down stairs"

- Answer: Social Model

2. Because of the stairs "Why was the hotel constructed only with stair access?"

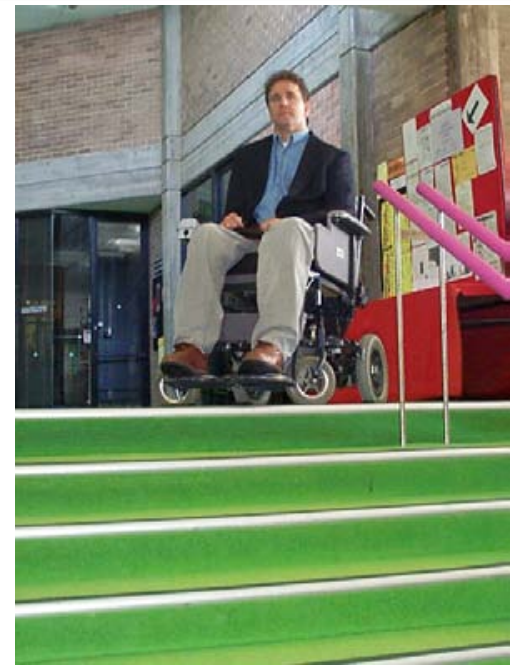


Table1: Emergent Themes and Representative Quotes

\section{Emergent Theme \\ Representative Quote}

Inclusive attitudinal "...it should be better than home so that we are delivering a memorable experience in approach that regard."

"So in terms of the general holiday experience is that, if you have got someone in a chair, they need to be part of the whole experience”.

Safety "I have a liability as general manager of the hotel to ensure that everyone has safe access to use all the facilities of the hotel and whether that is a ramp or making sure that something that is broken or dangerous is fixed, or highlighted for repair".

“...One particular example concerned the number of staff required to evacuate blind people in case of fire”.

Communication of "...difficult if they do not mention if they have a disability which makes it difficult to needs cater for their needs".

Public's perception "...the general public don't like to stay in those rooms."

of accessible rooms "...perception of market is that adapted rooms are of a lower standard”.

"They'll see that there's some water on the floor and realise it's the roll-in shower, and suddenly they find fault with the room, and once they have found something to complain about, they will keep going”.

Assistive equipment “...equipment which is specific for particular areas where access is poor like where we use stair climbers....all staff are trained to use this equipment”.

Legislation "I don't know anything specific but I know that certainly from a construction point of view there were guidelines that had to be followed".

“...there are problems in the adherence to minimum building codes. Instead of designing to provide the best possible disabled room they designed to provide the minimum features required for an accessible room".

Market Segment "It's interesting that seniors market is one we're trying to tap into at the hotel and the reason for that is because they've got disposable income and they've got time off during the week... but we hadn't thought of the disabled".

“...problems created by lack of information/knowledge rather than not wanting to do it”.

Staff training "...this training is mainly in cases of emergencies”.

"At induction staff are shown around the hotel, which includes the access rooms and its features are pointed out. There is no other formal training in respect of disability."

"issues with staff training, the need to provide staff with the expertise to understand the dimensions of disabilities and provide the confidence for staff to be able to interact with people with disabilities"

\begin{tabular}{ll}
\hline $\begin{array}{l}\text { Language, } \\
\text { marketing } \\
\text { promotion }\end{array}$ & $\begin{array}{l}\text { "we don't do anything specific to access apart from mentioning something on our } \\
\text { brochure or a fact sheet that we have X number of suites that a wheelchair accessible." } \\
\text { "...in chain of command between consumer and accommodation service provider the } \\
\text { information concerning special needs the specific information concerning this needs } \\
\text { tends to get lost in the chain". }\end{array}$ \\
\hline
\end{tabular}

